\title{
Organization Management in the Digital Economy
}

\author{
Ayna Salamova $^{1, *}$, Larisa Khatsieva ${ }^{2}$, Kh. U. Gishlakaeva ${ }^{3}$ \\ ${ }^{I}$ Chechen State University named after A.A. Kadyrov, Grozny, Russia \\ ${ }^{2}$ Grozny State Oil Technical University named after Academician M.D. Millionshchikova, Grozny, Russia \\ ${ }^{3}$ Chechen State College of Economics, Grozny, Russia \\ *Corresponding author. Email: salamova_chgu@mail.ru
}

\begin{abstract}
At the present stage, the issues of digitalization of economic processes and the penetration of information technologies into all areas of activity are very relevant. The aim of the study is to identify the features of enterprise management in the context of digitalization and the formation of an algorithm for implementing the process of digital transformation of an enterprise. The article presents the difference in terms of informatization and digitalization. The main features of enterprise management in the context of digitalization are considered. To implement the process of digital transformation of an enterprise, the authors proposed an adaptive algorithm, including the formation of an expert group, diagnostics of the enterprise's activities, development of a roadmap, implementation and testing. It is noted that when forming a roadmap, it is necessary to take into account the level of material and technical potential and the need for its modernization, as well as the level of the personnel potential of the enterprise and the need to improve the qualifications and level of motivation of the organization's employees.
\end{abstract}

Keywords: digitalization of economic processes, information technology, digital transformation of an enterprise, competitive advantages of an enterprise, optimization of business processes.

\section{INTRODUCTION}

At the present stage in the global information society, a new economic structure is being actively formed - digital [1]. There is a digitalization of economic processes and the penetration of information technologies into all spheres of activity. There are new requirements for the sources of competitive advantages of enterprises and effective concepts of their functioning and management. The relevance of issues related to the specifics of managing an industrial enterprise in the context of informatization and digitalization is of particular importance. It is necessary to organize the activities of the enterprise, taking into account the peculiarities of the transition to new principles of the digital economy, forecasting possible associated problems, as well as developing solutions and proposals to minimize negative consequences and enhance the main result of the enterprise. A significant competitive advantage can also be provided by a system of effective management of available resources and business processes in industrial enterprises based on innovative technologies and methods for optimizing business processes, which become the most important management tools through the continuous improvement of processes occurring in the enterprise and their optimization.

\subsection{Industrial organization in the digital economy}

The fourth industrial revolution (Industry 4.0) requires the organization's management to pay more attention to the use of "big data" in the analytics of production / service processes, energy-efficient technologies for the production of physical and digital twins of the product, as well as augmented reality technologies for equipment repair, cybersecurity when using a cloud service as part of collaboration on the project. The key technologies that provide a competitive advantage for an industrial organization in the context of digitalization include the following [8]:

- digital reverse engineering technologies that allow creating databases of digital models of technological equipment; - production technologies certified according to LEED (Leadership in energy and environmental design) and BREEAM (Building research establishment environmental assessment method); 
- information technologies that form a platform for the integration of product lifecycle management systems, corporate information systems and operational production management systems; artificial intelligence technologies in the organization management system; - radio frequency identification of industrial facilities using RFID tags (Radio frequency identification). The concept of the industrial Internet of Things IIoT (Industrial Internet of Things) involves the development of a network infrastructure not only within the industrial holding, but also outside when interacting with affiliates, branches, remote experimental production sites, contractors and counterparties [5-6]. Methodological recommendations for the organization and control of production processes based on the concept of lean production and cross-industry cooperation in an industrial organization are associated with the setting of the function of coordinating production activities, which is implemented through a certain number of stages [3]

1. The choice of a planning and accounting unit, common for all participants in the production process within the framework of network interaction (order, batch, assembly unit, backlog). 2. Determination of places for recording the results of production and economic activities (branch, subsidiary, independent business unit, temporary storage warehouse).

3. Determination of accounting technical and economic indicators (accounting currency, cost of marketable products, work in progress, output per worker)

4. Choice of the level of consolidation and aggregation of information using information technologies / systems (holding, affiliates, technological chain).

5. Determination of the time period for which data on production activity is provided by each of the participants in the network interaction.

6. The choice of information tools used to analyze the effectiveness of production activities (interactive data analysis, intellectual, statistical, dynamic).

7. Determination of the reporting forms used for the selected production task (periodically issued reports, non-regulated reporting), as well as its intermediate and end users within the corporate information system.

8. Determination of the conditions under which the actions of the participants of the integrated structure are coordinated (current coordination, unplanned situation).

9. Creation and periodic updating of a metadata repository throughout the entire life cycle of an industrial product from design to after-sales service.
The structure of the production management information system in an industrial organization is determined by the matrix "participation in assembly processes - the type of information systems support". An industrial organization, jointly implementing projects for the production of innovative types of products, can be, to varying degrees, involved in the intermediate and final stages of the production process. It can carry out exclusively nodal / general assembly or be guided by a mixed version (for some projects, groups of manufactured products, there are operations at all stages of the production process, for others - partially). In an industrial organization, the following are possible: organization of maintenance of the production management information system by the specialists of its own technical support service; contacting outsourcers (external companies that support all ongoing information processes); involvement of web-hosting of specialized applications (access to expensive software via the Internet). At the intersection of rows $\mathrm{A}$ and columns $\mathrm{B}$, quadrants of the $\mathrm{AB}$ matrix are formed, in which the preferred options for combinations of using information systems / IT technologies in managing production activities are determined, as well as a typical list of actions for integrating software and consolidating data. The initial data for starting the operation of any information system for production management in an industrial organization in the context of digitalization is information on the applicability of assembly units and parts in a product; manufacturability of product design; planning system (detailed, complete-assembly, complete-group, conditionally complete); operational and calendar plans; programs of launch-release of parts and assembly units [5].

\section{RESULTS AND DISCUSSION}

At the heart of the concept of the Program "Digital Economy in the Russian Federation", the key elements are information technologies, electronic services, as well as large amounts of data and new technologies for their transmission, processing, storage, management, analysis and formation of forecast indicators.

Within the framework of the Program, the following main problems that the state, society and organizations face in modern conditions can be identified [6]:

- the lack of a regulatory framework regulating the new economic order, or its inconsistency with technological changes taking place at the present stage of development; 
-the emergence of new technologies, objects and subjects of economic relations, the rapid growth of data volumes, which are becoming a form of capital;

-insufficient level of training of competent personnel, lack of human capital;

- a large amount of data generates a large number of information flows and risks associated with ensuring information security during the transfer, processing and storage of data;

- the emergence of new "end-to-end" technologies and applied solutions requiring infrastructure modernization.

Informatization is based on the massive introduction of information systems and technologies in order to increase the efficiency of all types of activities, improve working conditions and the quality of life of the population. Informatization covers information processes of various types in the socioeconomic and scientific-technical fields. The definition of "informatization" is a broader category than "digitalization". In recent years, the concept of "digitalization" has become increasingly used in connection with the widespread use of digital technologies for working with large amounts of data, the possibilities of their visualization, the emergence and dissemination of new technical means and software solutions. The management of enterprises in a new digital economic order should actively respond to changes in the external environment, be built taking into account the transparency and structure of all business processes, apply an effective knowledge management system and staff motivation, and also take into account the peculiarities of enterprise management in the context of digitalization [1-2 ].

When introduced into the activities of an enterprise, digital technologies provide a number of advantages, among which one can highlight an increase in production flexibility due to proactive changes in the characteristics of the production process and ensuring information integration of the stages of the life cycle of manufactured products. Digital transformation provides a qualitative improvement in the business processes of an enterprise through the introduction of innovations and the adaptation of business models to the conditions of the modern digital economy [7].

However, it is worth noting an increase in the level of dependence of production on the digital technologies used. It is necessary to make increased demands on digital technologies and take into account the possible damage from the failure of integrated digital systems, since it will be more significant in comparison with the traditional model of managing the production processes of an enterprise [4-5]. Industrial production is developing rapidly with a predominance of high-tech industries. New production technologies appear, develop and are introduced. By advanced manufacturing technologies (APT) we mean technologies and technological processes (including the equipment used) controlled by a $\mathrm{PC}$ or based on microelectronics and used in the production of goods and services.

To implement the process of digital transformation of an enterprise, the authors propose to use the following algorithm:

1. Formation of a competent expert working group capable of diagnosing the organization's activities and ongoing business processes;

2. Carrying out a self-examination of the enterprise and the formation of an array of initial data on the level of digitalization of the enterprise and production business processes, on the software components of digital production used;

3. Assessment of the level of digitalization (digital maturity) and the level of information security of the enterprise;

4. Identification of bottlenecks, determination of priority areas for the introduction of digital technologies, risk assessment;

5.Analysis of existing or development of new concepts of enterprise digitalization in the selected priority area;

6. Formation of a roadmap for the introduction of digital technologies;

7. Making a decision at the level of the head of the organization on the economic feasibility, efficiency of application and implementation of digital technologies in the activities of the enterprise, approval of the implementation roadmap;

8. Implementation of the roadmap for the introduction of digital technologies;

9. Control and analysis of implementation results and key performance indicators of the enterprise in order to make adjustments;

10. In the presence of positive dynamics, the study of scaling issues.

When forming the roadmap, it is worth taking into account the level of material and technical potential and the need for its modernization, as well as the level of the personnel potential of the enterprise and the need to improve the qualifications and level of motivation of the organization's employees. The modern way of the digital economy is characterized by the development of a new generation of enterprise management concepts, among which technologies can be distinguished that apply: artificial intelligence, robotics, drones, 3D printers, the Internet of Things 
(Internet of Things, IoT), blockchain innovation, and the possibilities of augmented and virtual reality. Applying new concepts gives businesses a competitive edge.

\section{CONCLUSIONS}

Thus, it can be noted that the decision to use modern technologies in management will affect the activities of the entire enterprise and it is necessary to take into account the associated risks. Obtaining the desired effect is possible only with careful planning and comprehensive study of promising technologies, their positive and negative sides, and it is also necessary to take into account the peculiarities of enterprise management in the context of digitalization. Building flexible organizational structures is possible with the use of digital information technologies. The management of an industrial enterprise in the era of digitalization imposes on the head of the organization requirements for professional knowledge, skills and abilities in the field of both management, personnel management, and in the field of IT technologies.

The proposed algorithm for implementing the process of digital transformation of an enterprise is adaptive and allows for the transition to a digital enterprise, which is also associated with cultural change and the transition to "digital thinking". It is necessary to carry out a lot of work on the creation of a socio-cultural environment of the enterprise, allowing to realize the advantages of the current stage of economic development, which is based on free interaction at all levels of management and readiness for changes.

\section{REFERENCES}

[1] V. P. Samarina, Problems of introducing information and communication technologies into modern Russian industry, 2019, pp. 88-91.

[2] A. Braverman, A. Saulin, Integral assessment of enterprise performance, 2019, pp. 108 -121.

[3] R. Brailey, S. Myers, Principles of Corporate Finance, 2020, pp. 132.

[4] A. Voronov, S. Rubanov, Sustainable development of the enterprise as a strategic goal of marketing, 3(2) (2018) pp. 31-37.

[5] E.V. Korchagina, Economic sustainability of an enterprise: types and structure. Problems of the modern economy, 3(15) (2018) pp. 68-71.

[6] Campbell Scientific Inc., Bowen Ratio system. Instruction manual. Logan, UT USA,2020, pp. 30.
[7] W. A. Dugas, Micrometeorological and chamber measurements of $\mathrm{CO} 2$ flux from bare soil Agricultural and Forest meteorology, 2018, pp. 115-128.

[8] A. S. Salamova, The theoretical foundations of institutionalism at the stage of accelerating globalization of international economic relations, 7 (2020) pp. 349-356.

[9] J. J. Andrea, C. Burns, J. Touza, Renewable Energy as a Luxury? A Qualitative Comparative Analysis of the Role of the Economy in the EU's Renewable Energy Transitions During the 'Double Crisis'. Ecological Economics, 142 (2020) pp. 81-90.

[10] J. Yang, F. Zhang, X. Jiang, W. Sun, Strategic Flexibility, Green Management, and Firm Competitiveness in an Emerging Economy. Technological Forecasting and Social Change, 101 (2018) pp. 347-356.

[11] K. Murtazova, M. Abdulkadirova, The Consumer Market in the New Economy, 2021, pp. 2-9. 